\title{
JOSÉ JUAN TABLADA TRADUTOR. A FACE MENOS EXPLORADA DO AUTOR EM UMA BREVE ANÁLISE
}

\section{JOSÉ JUAN TABLADA THE TRANSLATOR: A BRIEF ANALYSIS OF A LESS EXPLORED FACET OF THE AUTHOR}

\author{
Letícia Maria Vieira de Souza Goellner \\ Universidade de Brasília \\ Brasília, Distrito Federal, Brasil
}

\begin{abstract}
RESUMO: Neste artigo analisa-se o perfil tradutório do intelectual mexicano José Juan Tablada a partir das traduções que o autor realizou no início de sua carreira. Salientam-se os temas abordados em suas traduções como, por exemplo, o decadentismo que surge a partir da influência de Baudelaire. Somam-se a essa temática outras de diversos autores de língua francesa. Destaca-se principalmente a temática oriental que está presente em suas traduções e que posteriormente será central em seus escritos autorais. Como resultado, Tablada será reconhecido como um notável especialista da cultura japonesa.
\end{abstract}

PALAVRAS-CHAVE: José Juan Tablada; Literatura mexicana; Tradução; Japão; Haiku

\begin{abstract}
This article analyzes Mexican intellectual José Juan Tablada's profile as a translator based on translations he did at the beginning of his career. The themes addressed in his translations are explored, such as the decadence due to Baudelaire's influence, as well as themes derived from several other French-language authors. Of particular note is the Eastern theme in his translations, which would go on to become central to his writings and gain him recognition as a noted expert on Japanese culture.
\end{abstract}

KEYWORDS: José Juan Tablada; Mexican literature; Translation; Japan; Haiku 
José Juan Tablada foi um poeta, escritor, diplomata e jornalista mexicano que transitou entre os séculos XIX e XX, atuando neste período em escolas literárias importantes no continente, como o modernismo e o vanguardismo hispânicos ${ }^{1}$. O autor é considerado um dos principais representantes desses movimentos, sendo conhecido por sua poesia gráfica e, sobretudo, por seu pioneirismo na introdução da poesia japonesa em castelhano, especialmente o haiku. Em sua primeira etapa como jornalista, quando também publica seus primeiros escritos literários, o autor atuou como tradutor nos principais jornais e revistas do México, como El Universal, El País, El Imparcial, Revista de Revistas, Revista Moderna, Revista Moderna de México. Destaco deste grupo a Revista Moderna, que teve como um dos fundadores, e grande entusiasta, o próprio Tablada. O autor dedicou mais de 50 anos de sua vida ao jornalismo, publicando uma grande variedade de textos, sobre crítica de arte, crítica literária, teatro, seus poemas, crônicas, ensaios e algumas traduções.

Sabemos que a dupla função escritor-tradutor era uma prática comum, em boa parte dos periódicos, exercida pelos intelectuais da época. No caso de Tablada, no inicio de sua carreira, eram produzidas com certa regularidade traduções de temas diversos de escritores parnasianos e simbolistas, especialmente franceses. Uma particularidade nesse contexto de tradução de escritos majoritariamente provenientes do francês é a tradução de um poema que parece ter sido uma das raras traduções de Tablada da língua portuguesa para a espanhola, cujo texto fonte era de um poeta simbolista português. É o caso de "Rei Galaor" de Eugênio de Castro ${ }^{2}$. O texto, publicado na edição do mês de abril de 1902, contém nove páginas, com a tradução de Tablada do português para o espanhol, introdução e mais três páginas, com uma menção ao final da página que dizia simplesmente "continuará...". A sequência do texto traduzido só foi publicada três meses depois dessa aparição inicial, na edição de julho, embora tenha havido duas edições impressas intermediárias (edições de maio e junho), nas quais poderia ter sido publicado o restante da tradução. A finalização da tradução, portanto, a publicação completa do poema, foi concretizada sem nenhuma nota adicional que explicasse o hiato da publicação do texto em questão e, infelizmente, sem discussões a respeito do mérito ou o conhecimento do autor sobre a língua portuguesa. De qualquer forma, parece importante ressaltar que

\footnotetext{
${ }^{1}$ Este artigo foi extraído de parte da tese de doutorado, defendida em setembro de 2017, cujo título é "Tradução comentada de En el país del sol, de José Juan Tablada, para o português brasileiro", sendo modificado e atualizado para publicação neste periódico. Todos os detalhes sobre o autor, suas obras e traduções podem ser conferidas em Goellner (2017).

${ }^{2}$ Rei Galaor em espanhol, Revista Moderna, $1^{\text {a }}$ quinzena de abril, 4 primeiras páginas de tradução: <http://www.hndm.unam.mx/consulta/publicacion/visualizar/ 558075bf7d1e63c9fea1a422? intPagina $=2 \&$ tipo $=$ publicacion\&anio $=1902 \&$ mes $=4 \&$ dia $=1>$. Rei Galaor em espanhol, Revista Moderna, 2a quinzena de julho de 1902, 5 páginas restantes de tradução: <http:/www.hndm.unam.mx/consulta/publicacion/visualizar/ 558075bf7d1e63c9fea 1 a 422 ?intPagina $=6 \&$ tipo $=$ publicacion\&anio $=1902 \& \mathrm{mes}=7 \&$ dia $=$ $15 \&$ butIr $=$ Ir $>$.
} 
houve, ainda que possivelmente uma única vez ${ }^{3}$, o diálogo entre esse par de línguas e o interesse editorial desse periódico em publicar um texto originalmente escrito em português.

Através das traduções de Tablada podemos reconhecer as preferências e interesses literários do autor. Destaco o seu fascínio pela temática oriental e por esta ter sido introduzida em seus escritos desde o início de sua carreira, já no primeiro ano de publicação em um periódico. Pode-se notar um crescente interesse do autor por esse assunto que, provavelmente, pode ter sido intensificado e ampliado através do conhecimento abundante que adquirira por meio de suas traduções, especialmente de textos que retratavam o universo nipônico. Antecipo que, anos depois, o tema oriental ganhará notoriedade em suas próprias criações literárias e fará com que o autor mexicano se torne um reconhecido japonista.

Em 1891, temos a estreia de Tablada em periódicos, que se dá justamente através de suas traduções. Os primeiros textos traduzidos por ele são "El arte japonés", de Edmond de Goncourt, e "Una novela japonesa", de Judith Gautier. Entre os autores franceses traduzidos por Tablada merecem destaque os irmãos Goncourt, pois Edmond e Jules de Goncourt servirão de base e inspiração para a futura escrita do autor sobre o Japão.

Os textos traduzidos pelo autor mexicano aparecem citados por Velázquez (1995), em uma obra de catalogação de todos seus escritos publicados na imprensa. Nessa obra, a pesquisadora elenca traduções publicadas de textos franceses no jornal El Universal, em 1891. Tablada traduz Minuet, de Guy de Maupassant; El modelo e Gentleman, de Jean Richepin; fragmentos de La intrigante e El estreno, de Alphonse Daudet. Embora Tablada tenha traduzido diversos poetas de língua francesa, cabe destacar sua admiração e interesse por um poeta em especial, Charles Baudelaire. Dentre os textos traduzidos é importante mencionar dois deles: "A una madonna", publicado em 1892 (El Universal) e "Himno a la belleza", publicado em 1899 (Revista Moderna). Ambos poemas pertence a Les Fleurs du mal. ${ }^{6}$

Sobre "A una madonna" transcrevo, ao final deste parágrafo, os primeiros versos ${ }^{7}$; neles é possível constatar a inclinação do autor por temáticas

\footnotetext{
${ }^{3}$ Até o momento não foram identificadas, nesta pesquisa, outras traduções feitas por Tablada da língua portuguesa para a língua espanhola.

${ }^{4}$ Para consultar o texto de Baudelaire, traduzido por Tablada, "A una Madonna Ex voto". Acesse: $<$ http://www.hndm.unam.mx/consulta/publicacion/visualizar/ $\underline{558075 \mathrm{bf} 7 \mathrm{~d} 1 \mathrm{e} 63 \mathrm{c} 9 \mathrm{fea} 1 \mathrm{a} 475 \text { ? intPagina }=3 \& \text { tipo }=\text { publicacion } \& \text { anio }=1892 \& \mathrm{mes}=10 \& \text { dia }}$ $=23>$.

${ }^{5}$ Para consultar o texto de Baudelaire em francês e o traduzido por Tablada, "Himno a la beleza". Acesse: <http://www.hndm.unam.mx/consulta/publicac ion/visualizar/ $\underline{558075 \mathrm{bf} 7 \mathrm{~d} 1 \mathrm{e} 63 \mathrm{c} 9 \mathrm{fea} 1 \mathrm{a} 422 \text { ? intPagina }=33 \& \text { tipo }=\text { publicacion } \& \text { anio }=1899 \& \mathrm{mes}=10 \& \mathrm{di}}$ $\mathrm{a}=01>$.

${ }^{6}$ Em 1857 , publicada a $1^{\mathrm{a}}$ versão e em 1860 , a $2^{\mathrm{a}}$ versão.

${ }^{7}$ Para consultar o artigo na íntegra (El Universal, 23 oct, 1892, p. 5). Disponível em: $<$ www.hndm.unam.mx/consulta/publicacion/visualizar/558075bf7d1e63c9fea1a475?int Pagina $=3 \&$ tipo $=$ publicacion $\&$ anio $=1892 \&$ mes $=10 \&$ dia $=23>$.
} 
decadentistas em um certo período de sua escrita literária. O poema a seguir possui uma temática que será uma forte influência de Baudelaire em outros textos de Tablada escritos nesse mesmo período. Embora o poema consagrado sobre a incursão do autor em sua fase decadentista ${ }^{8}$ não tenha sido uma tradução e sim um poema de sua própria autoria intitulado "Misa negra" ${ }^{9}$, é fato que as traduções funcionavam como motivação para tratar essas ideias. $\mathrm{O}$ poema de Baudelaire expõe as temáticas abordadas por Tablada em diversos outros textos autorais, tais como: sacralização do amor, sacrilégios, erotização, melancolia.
A una Madonna (ex Voto)
En la fúnebre cripta de mi tristeza
lejos de las miradas y de las tierras, quiero, mi dulce amante, para tu gloria formar una capilla regia y suntuosa

Tablada dedica ao poeta francês inúmeras páginas em dezenas de periódicos através de suas críticas literárias, sempre fazendo comparações entre Baudelaire e um ou outro escritor, ressaltando as virtudes e qualidades poéticas do primeiro em detrimento dos demais. Tablada publica também, em 1893, uma análise de Les fleurs du mal, em primeira página de periódico ${ }^{10}$, na seção: "Fragmentos de un libro. Estudios literarios". Descreve a obra como um "jardim misterioso e sombrio" 11 e refere-se a Baudelaire com enorme entusiasmo como um autor que "fascina, hipnotiza, causa admiração, gênio, excepcional". E quando menciona o poema "À une madonne" (que ele mesmo já havia traduzido um ano antes desse estudo), relata que "hay partes en la obra que demuestran las aberraciones más imprevistas del sentimiento humano" e o autor segue mais adiante reafirmando que "En Baudelaire, la perversidad, la aberración de sentimientos, el libertinaje en el amor, llevado hasta el sadismo, los síntomas de la psicopatía más aguda, son caracteres que encuentra el más superficial análisis”. Em síntese, o que se pretende expor é a relação bastante acentuada entre Tablada e Baudelaire diante da admiração do autor mexicano pelo poeta francês e que em algumas etapas de sua escrita Tablada tenderá a entranhar-se ainda mais no universo decadentista de Baudelaire, sobretudo na virada do século XIX para o XX.

\footnotetext{
${ }^{8}$ Há muitíssimos estudos, ensaios e teses acadêmicas sobre a fase decadentista de Tablada, que neste trabalho é apenas citada. Podemos mencionar alguns textos que fazem referência a essa fase, como: Las veras y las burlas de José Juan Tablada, de Rubén Lozano Herrera (1995) ou o artigo de Esperanza Velázquez disponível em: $<$ http://cvc.cervantes.es/literatura/aih/pdf/14/aih_14_4_040.pdf $>$.

9 Publicado em El País, em 1893, o poema causou grande repercussão e polêmica, gerando, inclusive, o afastamento de Tablada do periódico.

${ }^{10}$ Para conferir o artigo na íntegra (SIGLO DIEZ Y NUEVE, 17 Jun, 1893, año 62). Disponível em: <http://www.hndm.unam.mx/consulta/publicacion/visualizar/ $558075 \mathrm{bf} 7 \mathrm{~d} 1 \mathrm{e} 63 \mathrm{c} 9 \mathrm{fea} 1 \mathrm{a} 43 \mathrm{f}$ ?anio $=1893 \& \mathrm{mes}=06 \& \mathrm{dia}=17 \&$ tipo $=$ publicacion $>$.

${ }^{11}$ Os trechos traduzidos para o português, sem menção de tradutores, são de minha autoria,
} 
Há algumas passagens obscuras na vida pessoal de Tablada e em suas reflexões narra tamanha influência de Baudelaire não somente em seus escritos, mas em sua postura perante a vida onde relata, por exemplo, sua relação com o abuso de drogas e imersão nos "paraísos artificiais":

La influencia de lo que en el poeta Baudelaire hay de morboso, fue para la juventud de mi generación el verdadero "Mal de las Galias"... Incapaces de discernir el artificio en la descarriada moral del gran poeta, fuimos más sinceros que él y desastrosamente intentamos normar no sólo nuestra vida literaria, sino también la íntima, por sus máximas disolventes creyendo así asegurar la excelencia de nuestra obra de literatos...El simple hecho de que Baudelaire hubiera llamado a alcoholes, drogas y estupefacientes "Los paraísos artificiales" iluminó las vulgares tabernas con esplendores de apoteosis luciferiana y las transformó, a nuestros ojos, en templos para la misteriosa iniciación artística. (TABLADA, 2010, p. 287).

Ainda sobre textos de Baudelaire relacionados a Tablada, segundo afirma Fernando Cisneros (2013, p. 429) em um verbete publicado no Diccionario Histórico de la Traducción en Hispanoamérica ${ }^{12}$, o autor mexicano publicou o poema "El fantasma" no jornal El Universal, como se fosse de sua autoria, apresentando-o como um texto inédito. Após questionamentos, no dia seguinte à publicação, o editorial do jornal anunciou que se tratava, na realidade, de um poema de Baudelaire traduzido por Tablada e não de um texto seu. Com isso, houve uma repercussão negativa que Cisneros relata: "La crítica que despertó, ambigua, fue condescendiente, al mencionar su juventud, pero aseveró también, inclemente: "la composición [...] ha perdido tanto al ser vertida, que... ni su sombra... ni fantasma siquiera es!" (CISNEROS, 2013, p. 429).

Outra tradução do francês feita por Tablada é o poema "Leonaine". Sobre este texto, o renomado pesquisador Rodolfo Mata (2011, p. 45) nos conta uma história polêmica, que envolve discussão sobre a autoria do poema. Segundo Mata, o poeta James Whitcomb Riley o teria publicado em 1877 como sendo um texto de sua autoria, que "imitaria" o estilo de Edgar Allan Poe. Porém, em 1904, o crítico Alfred Russel Wallace afirma, na revista Fortnightly Review, que o texto não poderia ter sido escrito por Riley, mas sim pelo próprio Edgar Allan Poe. A partir dessas datas, Rodolfo Mata supõe que a tradução do poema realizada por Tablada tenha ocorrido neste segundo momento, quando Wallace insiste na autoria de Poe, ressaltando o brilhantismo e características marcantes do poeta.

Sobre a influência que os poetas franceses exerciam em Tablada, o escritor mexicano Luis Gonzaga Urbina acrescentou:

Después de Rubén Darío y de Manuel Gutiérrez Nájera, ha sido José Juan Tablada el propagandista más avanzado de la actual estética francesa [...] De sus autores favoritos, de sus estudios y

\footnotetext{
${ }^{12}$ Dicionário editado por Lafarga e Pegenaute; para maiores detalhes conferir lista de referências ao final do texto.
} 
de sus lecturas, no ha tomado sino aquello que convenía a su temperamento y a la segura formación de su personalidad. Claro es que en la poesía de Tablada se siente la caricia de Baudelaire: se oye la voz unciosa de Verlaine [...]. (URBINA, 1903, p. 51).

Expandindo o contexto de traduções realizadas por Tablada vale mencionar e recuperar a questão de sua relação com textos japoneses mencionada previamente. Introduzimos essa breve exposição com uma suposta 'tradução direta do japonês' que teria sido feita pelo autor. Trata-se da pequena peça teatral El manto de penitencia, pertencente ao gênero comédia, de um único ato, de autoria desconhecida e que foi publicada em 1901 na Revista Moderna. A tradução direta desta peça de língua japonesa para o espanhol é discutível, uma vez que críticos especializados em Tablada, como Ruedas de la Serna, reforçam o fato do autor não ter conhecimento suficiente do japonês para fazer uma tradução direta e que ele teria utilizado uma versão em uma língua europeia, provavelmente o inglês ou o francês, para compor sua tradução. Ruedas de la Serna (2006, p. 208-219) inclui em sua edição crítica de En el país del sol, um apêndice com a tradução desta peça de 1901 e adiciona a tradução para o inglês de ir Basil Hall Chamberlain, publicada na Inglaterra em 1900, sugerindo que seria este o texto fonte utilizado por Tablada.

Temos também mais textos de temática japonesa, como os de José María de Heredia. Poeta nascido em Cuba e naturalizado francês, considerado um dos primeiros poetas parnasianos, publicou vários poemas de temática nipônica que atraíram Tablada. Dele, o autor mexicano traduziu os poemas "El Daimio" y "El samurai”, inserindo-os em na coletânea El florilegio, de 1904.

Outras importantes traduções realizadas por Tablada sobre temas japoneses são indicadas por Atsuko Tanabe (1981), entre elas de utas. Uta é um poema composto por 31 sílabas, geralmente escrito em um único verso, com variações encontradas de dois versos e com a divisão silábica de 5, 7, 5, 7, 7 sílabas. Tablada define a $u t a$ da seguinte forma:

Todas las pequeñas poesías que aquí figuran traducidas de poetas nipones se conocen en el Japón con el nombre de "utas" y pueden compararse con las seguidillas castellanas, los lieder alemanes o lays franceses del tiempo de Carlos de Órleans. El "uta" es generalmente el vehículo de la poesía popular, aunque muchos grandes poetas se hayan servido de él para expresar sus ideas. (TABLADA, 1991, p. 240).

De acordo com Tanabe, foram apenas treze as utas traduzidas por Tablada e publicadas em 1900 na Revista Moderna. Os poemas foram divididos em dois grupos sob os títulos: Utas japonesas- poetas del amor (publicado em outubro de 1900) e Cantos de amor y de otoño - Paráfrasis de poetas japoneses - del 'Kokiñshifu (publicado em dezembro de 1900). Embora seja reduzido ${ }^{13}$ o número

\footnotetext{
${ }^{13}$ Número reduzido, sobretudo, se comparado ao texto fonte utilizado por ele que comprova que tanto a coleção imperial original de 905 quanto a de 1205 eram compostas
} 
de utas traduzidas pelo autor, a extrema importância dessa experiência reside em seu ineditismo no âmbito do idioma. Tanabe (1981, p. 52) chama a atenção para o fato de Tablada ter traduzido essas utas vinte anos antes de publicar seu livro de haiku. Portanto, pode-se inferir, pelas ponderações da pesquisadora, que a intimidade do autor com esses poemas concisos, e de grande expressão poética, tenham contribuído fortemente para consagrá-lo, duas décadas depois, quando publica seus próprios poemas, como o principal representante hispano-americano do haiku japonês, .

A tradução das utas de Tablada podem ser como paráfrases, que envolvem um processo pessoal de reformulação textual. No estudo de Tanabe (1981), são apresentados vários exemplos de traduções das utas com os textos originais em japonês, algumas delas com as traduções de Basil Hall Chamberlain, e o que se supõe sejam as respectivas versões de Tablada. Tanabe também apresenta traduções literais para o espanhol, feitas por ela, para auxiliar o leitor no entendimento do significado dos versos em japonês. Esses exemplos são acompanhados de considerações teóricas sobre tradução poética e impossibilidade de tradução. Destacamos o que o próprio Tablada comenta sobre a tradução da poesia japonesa em seu livro Hiroshigué ${ }^{14}$ : “[...] Pero resulta irreverente traducir esta clase de poesías japonesas que, originales, tienen una admirable concisión impresionista, y vertidas parecen incoherentes. No las gustará quien no las lea en japonés. (TABLADA, 1914 [versão digitalizada, s/d], p. 37).

Tomemos como exemplo uma das utas, anônima, traduzida por Chamberlain e Tablada. Nota-se que Tablada utilizou o texto inglês como fonte para sua tradução/recriação, ou paráfrase e, em muitos outros poemas, percebe-se o uso da mesma grafia utilizada por Chamberlain (incluindo seus erros ortográficos). Eis o poema, reproduzido em Tanabe (1981, p. 61):

\title{
Texto de partida (romanizado)
}

\author{
Kinõ Koso \\ Sanae torishika \\ Itsuno mani \\ Inaba soyoguite \\ Akikaze no fuku
}

\begin{abstract}
de pelo menos vinte volumes, contendo entre 1.100 e 1.900 poemas e com uma enorme diversidade temática.

${ }^{14}$ Obra que o autor mexicano dedica a Edmond de Goncourt. Trata-se de uma edição tão rara quanto bela, que contou com apenas trinta exemplares e que foi digitalizada, incluindo uma série de imagens importantes que demonstram a relação entre a pintura japonesa e a poesia de Tablada e revelam um japonismo consolidado e profundo do autor. Rodolfo Mata é o editor responsável pela versão digital de Hiroshige. Para ter acesso à obra completa digitalizada $\mathrm{e}$ todas as imagens oferecidas:

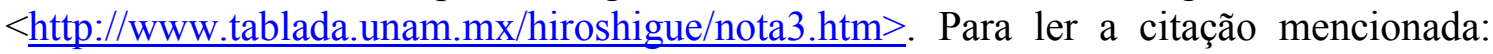
$<$ http://www.tablada.unam.mx/hiroshigue/p044.htm $>$.
\end{abstract}




\title{
Tradução literal (oferecida por Tanabe) ${ }^{15}$
}

\author{
Apenas ayer \\ Recogimos los retoños de arroz \\ Y sin saber desde cuándo ya, \\ Sobre los arrozales susurrantes \\ Va pasando una brisa otoñal \\ Tradução de Chamberlain
}

Can I be dreaming? 'Twas but yesterday

We planted out each other tender shoot again;

And now the autumn breeze sighs o'er the plain,

Where fields of yellow rice confess its sway.

\section{Tradução de Tablada}

\begin{abstract}
¿Estoy soñando acaso?... Ayer en Primavera
Miramos la esmeralda temprana del retoño

Y ya una triste brisa suspira en la pradera

Entre los amarillos arrozales de Otoño!
\end{abstract}

Comparando as traduções de Chamberlain e Tablada, Tanabe destaca o colorido da versão tabladiana e o uso da substantivação de adjetivos. Cita o caso de "esmeralda del retoño" ao invés de "retoño verde", por exemplo. Já a tradução de Chamberlain é amplificada e explanatória, se a comparamos com a tradução oferecida por Tanabe.

Outra amostra pertinente é a tradução de um poema que consta nas utas volume IX (Cantos de despedida), de Murasaki Shikibu O poema traduzido por Tablada tem como tema a despedida de uma grande amiga. A seguir, reproduzo o poema tal qual aparece no estudo de Tanabe (1981, p. 65-66):

\section{Texto de partida (romanizado)}

Kita e yuku

Kari no tsubasa ni

Kotozuteyo

Kumo no uwagaki

Kaki taezu shite

\section{Tradução literal}

Encargad vuestros mensajes

A las alas de ocas salvajes

Que vuelan hacia el norte

Sin cesar de escribir

Los sobrescritos de nubes.

${ }^{15}$ A tradução deste e do próximo poema é oferecida por Tanabe (1981, p. 61). 


\section{Tradução de Tablada}

Cuenta, hermosa, tu tormento

A las garzas mensajeras,

Que con vuelo blando y lento

¡sobre el azul firmamento

Trazan estrofas ligeras!

Tanabe observa que Tablada confere à tradução muito mais movimento que o texto de partida e que reforça a sensação visual através da cor, além de deixar o poema mais explicativo do que a versão japonesa. Tablada utiliza recursos muito usados pelos modernistas, como itens lexicais com alusão às cores. Esse artifício das cores também é largamente aplicado nas crônicas japonesas examinadas na minha tese, citada no início deste artigo (GOELLNER, 2017).

Em suas traduções de utas, Tablada parece manter o diálogo com o texto de partida, porém se concede o direito de criar, acrescentar e produzir o que considera ser a sensação poética, o sentido do poema e o estilo das utas, sem estar rigorosamente apegado à letra. No último exemplo, o autor explicita o que o texto de partida apenas sugere e faz modificações e acréscimos, como o nome da ave. Sob o ponto de vista da tradução, baseada nas tendências deformadoras de Berman (2013), Tablada estaria clarificando algo que intencionalmente estava subentendido.

John Milton (2010) aborda a paráfrase de acordo com a concepção de Dryden; poderíamos considerar as traduções das utas feitas por Tablada como paráfrases ou traduções com latitude. De acordo com essa ótica, "o autor é mantido ao alcance dos nossos olhos... porém suas palavras não são seguidas tão estritamente quanto seu sentido, que também pode ser ampliado, mas não alterado". (MILTON, 2010, p. 50).

Partindo de uma visão menos permissiva e avaliando essa liberdade que Tablada se concede ao traduzir as utas, poderíamos encará-la como uma tradução não-estrangeirizante, que, no sentido extremo, não valorizaria de maneira completa a cultura do Outro, já que os poemas, segundo a crítica, tratam em profundidade a alma japonesa e o olhar nipônico da natureza. Essa postura tradutória estaria em contradição com o que Tablada pratica em toda sua vida literária, de reverência à cultura japonesa em seus mínimos detalhes. Destaco que Tablada não só entende e absorve o aprendizado com o estrangeiro como tenta alcançar o que em japonês se denomina kokoro que, de maneira simplificada, podemos entender como "alma, sentimento, coração das coisas".

As considerações feitas por Célia Prado (2011), que embora tratem de contextos e autores aparentemente alheios aos textos de Tablada, podem ser aproveitadas para reflexão sobre a tradução feita por ele no caso das utas. A pesquisadora tece comentários a respeito de um poema traduzido por Manuel Bandeira. Trata-se de um poema de Pierre de Ronsard, que em português obteve o 
título: "Soneto de Ronsard" 16 e em edições posteriores "Paráfrase de Ronsard". A primeira relação que podemos traçar entre Ronsard e Tablada consiste em que ambos os escritores são inovadores em suas práticas poéticas e utilizam estratégias de aproximação aos textos clássicos. Ronsard tem como inspiração a lírica grega; em Tablada, o elo é com a poesia milenar japonesa através das utas. Outra aproximação possível é com o método de tradução de Bandeira e de Tablada. Prado (2011, p. 10) argumenta que Manuel Bandeira exibe qual é o texto fonte para sua tradução e ao mesmo tempo "explicita uma espécie de coautoria", com forte base na apropriação do texto como tradutor, desmistificando o "texto sagrado, texto original", e nesse sentido as ponderações de Prado podem ser aplicadas à postura tradutória de Tablada em relação às utas:

Nessa cumplicidade revelam-se, concomitantemente, os aspectos dialógico e interpretativo do processo, sendo que o termo paráfrase traz em sua composição o prefixo grego pará- que reforça o aspecto de contiguidade e continuidade. A liberdade assumida na recriação do poema faz transparecer o conceito de paráfrase como um processo que não pretende reproduzir, mas produzir algo diferente, sem perder de vista o poema que o motivou. (PRADO, 2011, p. 165).

Para concluir, posso dizer que este artigo procurou desvelar alguns aspectos do perfil tradutório do poeta mexicano. Tablada procurou, em boa parte de sua vida literária, reproduzir e traduzir através de imagens sofisticadas, em inúmeros textos de sua autoria, um Japão requintado e sutil. Com o exame do exíguo corpus de textos por ele traduzido, foi possível observar que seu conhecimento sobre a temática japonesa se deu desde os primeiros textos com os quais teve contato no início de sua carreira e que sua prática tradutória pode ter servido como um estímulo para a sua obra própria. Podemos pressupor que, de alguma forma, essas traduções serviram de base para a ampliação da visão que o autor tinha incialmente sobre o Japão e que foi refinando ao longo de sua carreira literária.

\section{REFERÊNCIAS}

BERMAN, Antoine. A tradução e a letra ou o albergue do longínquo. Tradução Marie- Hélène C. Torres; Mauri Furlan; Andreia Guerini. $2^{\mathrm{a}}$ edição. Tubarão: Copiart, 2013.

CISNEROS, Fernando. Diccionario histórico de la traducción en Hispanoamérica. Francisco Lafarga y Luis Pegenaute (Ed.). Frankfurt: Vervuert; Madrid:

\footnotetext{
${ }^{16} \mathrm{O}$ leitor pode consultar o poema em francês e a tradução de Manuel Bandeira, bem como a análise dessa tradução feita por Célia Prado em: < http://www.revistas.usp.br/ tradterm/article/view/36760/39482>.
} 
Iberoamericana, 2013. Disponível em: <http://www.elem.mx/autores/ ficha_diccionario/1037>. Acesso em 10 out. 2016.

GOELLNER, Letícia. Tradução comentada de En el país del sol, de José Juan Tablada, para o português brasileiro. Tese (doutorado) - Programa de PósGraduação em Estudos da Tradução, Universidade Federal de Santa Catarina Florianópolis. Acesso em 14 jul. 2017. Disponível em:

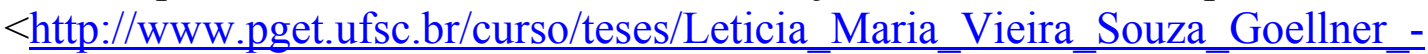
Tese.pdf $>$.

MATA, Rodolfo. José Juan Tablada: Translator. Nicholas Goodbody (Trad.). Translation Review. Guest Editors Carmen Boullosa and Regina Galasso. Special Issue, 81, Spring 2011. Acesso em 12 jul. 2017. Disponível em: $<$ http://www.tandfonline.com/doi/abs/10.1080/07374836.2011.10555801>

MILTON, John. Tradução Teoria e Prática. São Paulo: Martins Fontes, 2010.

PRADO, Célia. Tradução, Paródia e paráfrase: as reescrituras poéticas de Manuel Bandeira. Revista TradTerm, São Paulo, v. 18, p. 1-23, 2011.

RUEDAS DE LA SERNA, Jorge. "Prólogo". In: TABLADA, José Juan. En el país del sol. Obras completas VIII. Edición crítica. Presentación de José Pascual Buxó. Ciudad de México, D.F.: Coordinación de Humanidades. Programa editorial Universidad Nacional Autónoma de México, 2006, p. 17-61.

TABLADA, José Juan. Obras completas IX. La feria de la vida. Memorias I, de José Juan Tablada. Estudio introductorio y notas de Fernando Curiel Defossé. Coordinación de Humanidades. Programa editorial. Ciudad de México: Universidad Nacional Autónoma de México, 2010.

TABLADA, José Juan. Hiroshigué: el pintor de la nieve y de la lluvia, de la noche y de la luna. México: 1914. (Monografias Japonesas). [versão digital [s/d]. Disponible en: $<$ http://www.tablada.unam.mx/hiroshigue/portada.htm $>$. Acesso em 10 jul. 2017.

TABLADA, José Juan. Obras completas I. Poesía. Recopilación, edición, prólogo y notas Héctor Valdés, $1^{\text {a }}$ reimpresión. Instituto de Investigaciones Filológicas, Centro de Estudios Literarios. Ciudad de México: Universidad Nacional Autónoma de México, 1991.

TANABE, Atsuko. El japonismo de José Juan Tablada. Ciudad de México: Universidad Nacional Autónoma de México, 1981. Colección Seminarios.

URBINA, Luis Gonzaga. "José Juan Tablada". Revista Moderna. Ciudad de México, n. 4, año VI, $2^{\mathrm{a}}$ quincena, febrero, 1903, p. 51. Disponível em: $<$ http://www.hndm.unam.mx/consulta/publicacion/visualizar/558075bf7d1e63c9f ea1 a422? intPagina $=3 \&$ tipo $=$ publicacion $\&$ anio $=1903 \&$ mes $=02 \&$ dia $=15>$. Acesso em 7 jul. 2017. 
VELÁZQUEZ, Esperanza Lara. Catálogo de artículos de José Juan Tablada en publicaciones periódicas mexicanas: 1891-1945. Ciudad de México: Universidad Nacional Autónoma de México. 1995.

Letícia Maria Vieira de Souza Goellner Lele.Goellner@gmail.com

Recebido em: 8/10/2017

Aceito em: $4 / 2 / 2018$

Publicado em Abril de 2018 